\title{
Identification of polymorphisms associated with production traits on chicken (Gallus gallus) chromosome 4
}

\author{
F. Pértille', R. Zanella ${ }^{2}$, A.M. Felício', M.C. Ledur' ${ }^{2}$, J.O. Peixoto² and L.L. Coutinho' ${ }^{1}$ \\ ${ }^{1}$ Labortório de Biotecnologia Animal, Departamento de Zootecnia, \\ Escola Superior de Agricultura "Luiz de Queiroz", Universidade de São Paulo, \\ Piracicaba, SP, Brasil \\ ${ }^{2}$ Embrapa Suínos e Aves, Concórdia, SC, Brasil \\ Corresponding author: L.L. Coutinho \\ E-mail: Ilcoutinho@usp.br \\ Genet. Mol. Res. 14 (3): 10717-10728 (2015) \\ Received December 9, 2014 \\ Accepted July 15, 2015 \\ Published September 9, 2015 \\ DOI http://dx.doi.org/10.4238/2015.September.9.11
}

\begin{abstract}
Genetic selection for production traits has resulted in a rapid improvement in animal performance and development. Previous studies have mapped quantitative trait loci for body weight at 35 and 41 days, and drum and thigh yield, onto chicken chromosome 4. We investigated this region for single nucleotide polymorphisms and their associations with important economic traits. Three positional candidate genes were studied: KLF3 (Krüeppel-like factor 3), SLIT2 (Slit homolog 2), and PPARGC1A (peroxisome proliferator-activated receptor gamma, coactivator 1 alpha). Fragment sequencing of these genes was conducted in $11 \mathrm{~F}_{1}$ animals, and one polymorphism in each gene was selected and genotyped in an $\mathrm{F}_{2}$ population $(N=276)$ and a paternal broiler line TT $(N=840)$. Associations were identified with growth, carcass, and fat traits in the $F_{2}$ and the paternal line $(P<0.05)$. Using single markers in both the $F_{2}$ and the TT line, KLF3 was associated with weight gain ( $P<0.05)$, PPPARGC1A was associated with liver and wing-parts weights and yields $(P<0.05)$, and SLIT2 was associated with back yield $(P<0.05)$ and fat traits $(P<0.05)$.
\end{abstract}


Using multiple markers, KLF3 lost its significance in both populations, and SLIT2 was associated with feed conversion only in the TT population ( $P$ $<0.05)$. The QTLs mapped in the $F_{2}$ population could be partly explained by PPARGC1A and SLIT2, which were associated with body weight at 35 and 41 days, respectively, and with drum and thigh yield in the same population. The results of this study indicate the importance of these genes for production traits.

Key words: Broiler; Production trait; Candidate gene; Polymorphism; QTL

\section{INTRODUCTION}

Selection for production traits in the poultry industry (broiler and layer) has resulted in a rapid improvement in animal performance. For broilers, the main selection pressure has been on growth rate, feed efficiency, and carcass traits, and in layers, the focus has been to increase egg production and quality (Fulton, 2012). However, although several traits have been genetically improved, phenotypic and genetic variations still exist among chicken populations due to differences in selection practices imposed by different breeding programs; therefore, improvements are required in this regard (Rönnegård and Valdar, 2011).

To obtain considerable genetic gain in a selection program, it is necessary to understand the population structure and the genetic architecture of the traits to be selected for, in order to avoid deleterious effects. With the advantage of DNA investigation technologies, the ability to identify molecular markers that are used to construct linkage maps has improved (Mackay, 2001), allowing the detection of hundreds of quantitative trait loci (QTLs; dbQTL, http://www.animalgenome.org/cgibin/QTLdb/index). Several studies using microsatellite markers have identified QTLs associated with production traits across the chicken genome (Zhou et al., 2006; Ambo et al., 2008, 2009; Campos et al., 2009; Ankra-Badu et al., 2010; Baron et al., 2010; Nones et al., 2012; Nassar et al., 2013). Other studies that have used single nucleotide polymorphism (SNP) markers have identified genetic associations and linkage with production, health, and behavioral traits in farm animals (Zanella et al., 2011; McSpadden et al., 2013).

Important QTLs have been identified on chicken chromosome 4 (GGA4) between the markers MCW0240 and LEI0063, which are associated with body weight at 35 and 41 days of age and drum and thigh yield, respectively, in Embrapa $F_{2}$ chicken population (Ambo et al., 2009; Baron et al., 2010). These QTLs alone explained $4.27 \%$ of the phenotypic variance for body weight at 35 days and $5.26 \%$ for body weight at 41 days of age in the population studied (Ambo et al., 2009), and $2.66 \%$ of the phenotypic variance for drum and thigh yield (Baron et al., 2010) in the same population. Five QTLs overlapping this region that are associated with body weight have also been identified (Rabie et al., 2005; Hocking et al., 2012): one for abdominal fat weight (Jennen et al., 2004) and another for abdominal fat yield (Ankra-Badu et al., 2010).

Initial investigations of this region have resulted in the identification of a polymorphism located at 76,163,331 bp G>A on FGFBP1 (protein binding growth factor fibroblast 1), which is associated with eviscerated carcass weight in a commercial broiler line. This polymorphism is also associated with protein and ash content in Embrapa $F_{2}$ chicken population (Felício et al., 2013).

However, single-marker studies cannot precisely identify regions that harbor causative mutations. To increase our knowledge of this important QTL on GGA4, in this study, three additional 
genes positioned between markers MCW0240 and LEI0063 were sequenced in a $\mathrm{F}_{1}$ population in order to detect SNPs, and their associations with important growth and carcass traits, in an $\mathrm{F}_{2}$ and a paternal broiler line.

\section{MATERIAL AND METHODS}

\section{Populations and phenotypic measurements}

We used two Brazilian chicken populations: Embrapa $F_{2}$ chicken resource population and the TT reference population.

\section{Embrapa $F_{2}$ chicken resource population}

Our studies with the chicken genome started in 1999 with the development of the experimental $F_{2}$ population of a cross of a parental broiler line (TT) and a layer line (CC), at the Embrapa Suínos e Aves National Research Center. To produce the $F_{2}$ population, one $F_{1}$ male (TC) and three $F_{1}$ females (TC) were selected from different $F_{1}$ families and randomly mated with non-related animals. Seven males and twenty-one females from each $F_{1}$ cross (TC) were used to generate $100 \mathrm{~F}_{2}$ animals per $\mathrm{F}_{1}$ family across 17 hatches in intervals of 15 days for approximately eight months, which resulted in $2063 \mathrm{~F}_{2}$ chickens (TCTC) with a 50:50 sex ratio. The animals were tagged with their individually unique pedigree, reared as broilers, and evaluated for 51 phenotypic traits. Due to phenotypic differences between the TT and CC lines, the $F_{2}$ animals that resulted from their cross are ideal for QTL identification. A more detailed description of the animals and phenotypic measurements is provided by Nones et al. (2006).

The $\mathrm{F}_{2}$ population phenotypes were classified as carcass (wing, head, carcass, back, drum and thigh, breast, feet, heart, liver, gizzard, and lung weights and yields), performance (feed intake, weight gain, and feed conversion from 35 to 41 days, body weight at $1,35,41$, and 42 days, and length of the intestine), and fat (cholesterol, triglyceride, and cholesterol plus triglyceride content, abdominal fat weight, and abdominal fat yield). The weights were measured in grams $(\mathrm{g})$, length in centimeters $(\mathrm{cm})$, and content in $\mathrm{mg} / \mathrm{dL}$. A more detailed description of the animals and phenotypic measurements is provided by Nones et al. (2006), Campos et al. (2009), and Baron et al. (2010).

\section{TT reference population}

The TT reference population was developed in 2008 at Embrapa Suínos e Aves National Research Center. It originated from the expansion of the paternal broiler line (TT), which has been under selection since 1992 in order to improve body weight, feed conversion, carcass yield, viability, fertility, and hatchability. The TT reference population has approximately 1500 animals from five hatches, which originated from a cross of 20 males with 92 females (1:5). Several performance and carcass traits $(\mathrm{N}=85)$ were evaluated, and blood and tissue samples were collected during slaughter at 42 days and kept at $-80^{\circ} \mathrm{C}$ for DNA extraction (Peixoto et al., 2011).

Eight performance traits were evaluated: birth weight, body weight at $21,35,41$, and 42 days of age, feed intake, weight gain, and feed conversion from 35 to 41 days. The carcass traits evaluated were as follows: carcass, drumsticks, drums and thighs, back, breast, breast fillet, breast muscle, drumstick muscle, drum and thigh muscles, feet, head, neck, wings, wing sticks, 
middle-joint wings, wing tips, post-bleeding and plucking carcass, heart, liver, gizzard, lungs, and abdominal fat weights and their yields, totaling 42 traits. The weights were evaluated in grams and yields in percentages related to body weight at 42 days of age.

Animals from both populations $\left(\mathrm{F}_{2}\right.$ and TT reference population) were raised in communal boxes up to 35 days of age, and from 35 to 41 days they were moved to individual cages for feed conversion evaluation. The animals all received the same diet, which was composed of $20 \%$ crude protein (CP) and $3200 \mathrm{kcal}$ of metabolizable energy (ME) from 1 to 21 days of age, and from 22 to 41 days of age they received a diet composed of $18.5 \% \mathrm{CP}$ and $3200 \mathrm{kcal} \mathrm{ME}$. Slaughter was conducted after $6 \mathrm{~h}$ of fasting on day 42 . The two populations used in this study have a complete DNA and phenotypic data bank, and complete pedigree information is available for each individual.

\section{DNA extraction}

Genomic DNA was extracted from $20 \mu \mathrm{L}$ of blood from $11 \mathrm{~F}_{1}, 276 \mathrm{~F}_{2}$, and $850 \mathrm{TT}$ chickens with $500 \mu \mathrm{L}$ of DNAzol ${ }^{\circledR}$ Reagent, following the manufacturer protocol (Life Technologies Invitrogen). DNA samples were quantified and their quality and concentration measured using a NanoDrop ${ }^{\circledR}$ 2000c spectrophotometer (NanoDrop, Wilmington, DE, USA) and diluted to a working concentration of $25 \mathrm{ng} / \mu \mathrm{L}$.

\section{Candidate gene and SNP discovery}

A QTL for body weight at 35 and 42 days of age (Ambo et al., 2009) and drum and thigh yield (Baron et al., 2010) was mapped between 67,652 and 81,169 kb on GGA4, flanked by MCW0240 and LEI0063 microsatellites. One-hundred-and-forty-two genes are located in this region (http://www.ncbi.nlm.nih.gov/mapview/, accessed March 24, 2011), including FGFBP1 (Felício et al., 2013). Three positional candidate genes were selected on the National Center for Biotechnology Information (NCBI) gene database, based on their location in the QTL and their biological function that was related directly or indirectly with growth.

KLF3 (Krüeppel-like factor 3; Gene ID 51,274) is located on GGA4 between $69,144,274$ and 69,158,078 bp (Sue et al., 2008) (NC_006091.3). A region of approximately $500 \mathrm{bp}$ between the first and second intron on $K L F 3$ was sequenced using Primer 1 (F, 5'-TTGGGAAAGAAAAAGCCTAACA-3'; R, 3'-CAGAGGTCATTTAGGGGCAA-5'). PPARGC1A (peroxisome proliferator-activated receptor gamma PPAR-Y; Gene ID 422,815) is located on GGA4 between 73,626,292 and 73,688,018 bp (NC_006091.3) (Esterbauer et al., 1999). A region of approximately $500 \mathrm{bp}$ between the first and second intron on PPARGC1A was sequenced using Primer 2 (F, 5'-TGTTTCTACATTGCTGTTTCCTG-3'; R, 3'-GCAACTCCTCCTTGTTACGC-5'). SLIT2 (Slit homolog 2 protein; Gene ID 373,967) is located on GGA4 between 74,558,606 and $74,803,058$ bp (NC_006091.3) (Kidd et al., 1999). A region of approximately 500 bp between the 10th and 11th intron on SLIT2 was sequenced using Primer 3 (F, 5'-TGCCACTCATTTGGGAATATC-3'; R, 3'-TCTACATCTTTCAGCATTGATTGA-5').

Sequencing was conducted in $F_{1}$ animals that were segregating the associated QTL based on previous studies (Felício et al., 2013). Primers were designed using the Primer3 program (http://frodo.wi.mit.edu/) based on sequences from GenBank (www.ncbi.nlm.nih.gov), and quality analysis was performed using the NetPrimer software (www.premierbiosoft.com/netprimer). After optimization of the polymerase chain reaction (PCR) conditions and amplification of the fragments, 
the PCR products were purified using a PCR Purification Protocol for sequencing using Agencourt ${ }^{\circledR}$ AMPure XP with magnetic beads. Following purification, the fragments were sequenced using an automated ABI PRISM ${ }^{\circledR} 3130$ Genetic Analyzer (Applied Biosystems). For nucleotide sequence editing, assembly, analysis, alignment, and polymorphism identification, Phred (Jacobs, 1985), Phrap (Ewing et al., 1998), and Consed (Gordon et al., 1998) were used.

\section{Genotyping}

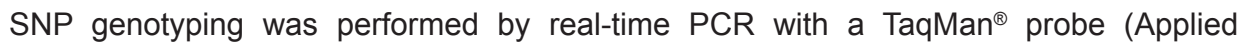
Biosystems) in a LightCycler 480 System $\|^{\circledR}$ (Roche), using an endpoint genotyping with a dual color hydrolysis detection format (FAM and VIC fluorescence probes). InDel genotyping was

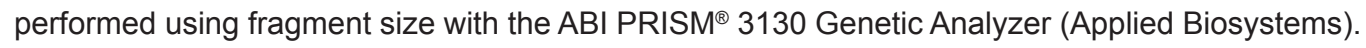

\section{Statistical analysis}

A general mixed model that included additive and dominance SNP effects was run using QxPak 4.0 (Pérez-Enciso and Misztal, 2004), in order to test for single- and multiple-marker associations in the $F_{2}$ and TT populations. The model also included sex as a fixed factor, in order to verify whether the SNP effect was influenced by sex. Significance was set at the $\mathrm{P}<0.05$ level. The full model was as follows:

$$
Y_{i j k l}=\mu+a_{i j k}+I_{i}+S_{j}+S N P_{k}+e_{i j k l}
$$

where $Y_{i j k l}$ is the animal's phenotype, $\mu$ is the overall population mean, $a_{i j k}$ is the random animal term, $I_{i}$ is the fixed effect of hatch, $S_{j}$ is the fixed effect of sex, $S N P_{k}$ is the SNP fixed effect, and $e_{i j k l}$ is the residual error.

Body weight at 35 days was used as a covariate for the following performance traits: feed intake, weight gain, and feed conversion from 35 to 41 days in both populations, while body weight at 42 days was used as a covariate for carcass traits only in the $F_{2}$ population.

For the multiple marker association tests, the same model was used with the inclusion of multiple SNPs that were tested at the same time. The HaploView program (Barrett et al., 2005) was used to calculate pairwise measures $\left(r^{2}\right)$ of linkage disequilibrium (LD) between SNPs using the maximum-likelihood values for the four gametic frequencies. The Hardy Weinberg equilibrium (HWE) was calculated using a chi-square goodness-of-fit test based on deviations from heterozygosity, where the predicted heterozygosity (PredHET) was obtained with the following formula:

$$
\text { PredHET }=2 \times M A F \times(1-M A F)
$$

(Equation 2)

\section{RESULTS}

The novel polymorphisms identified on KLF3, PPARGC1A, and SLIT2 were located on GGA4 at 69,144,312 bp (C>T) (NCBI_ss831878770), 73,632,140 bp (-/CTTTTT) (NCBI_ ss831878773), and 74,737,073 bp (C>A) (NCBI_ss831878772), respectively. 


\section{Frequencies and association analyses}

For the TT population, polymorphisms were identified in $K L F 3(\mathrm{C}>\mathrm{T})$ with an allelic frequency of $0.98(\mathrm{C})$ and $0.02(\mathrm{~T})$, and genotypic frequencies of $0.96(\mathrm{CC}), 0.04(\mathrm{TC})$, and 0.00 (TT). For PPARGC1A (-/TTTCT), the allelic frequency was 0.33 (Del) and 0.67 (In), and the genotypic frequencies were 0.11 (Del/Del), $0.44(\mathrm{In} / \mathrm{Del})$, and $0.45(\ln / \mathrm{ln})$. For SLIT2 (C>A), the observed allelic frequency was $0.3(A)$ and $0.7(C)$, and the genotypic frequencies were $0.08(A A)$, $0.44(A C)$, and $0.48(C C)$. None of the markers deviated from the HWE. The low level of LD found between the markers in both populations $\left(r^{2}<0.03\right.$ for $F_{2}$ and $r^{2}<0.27$ for TT) may be explained by the long spacing between the studied markers.

Using a single marker association test for the $F_{2}$ and TT populations, the additive model best explained the effects of the SNPs located on KLF3 and SLIT2. For PPARGC1A, the model with additive and dominance effects had the best fit. There was no interaction between the SNP effect and sex. The associations between the two SNPs and the InDel and the traits evaluated in the $\mathrm{F}_{2}$ and TT populations are shown in Tables 1 to 4 , as are their additive and dominance effects.

\begin{tabular}{|c|c|c|c|c|c|c|c|}
\hline \multirow{3}{*}{$\overline{F_{2} \text { population }^{1}}$} & \multirow[t]{3}{*}{ Trait } & \multicolumn{4}{|c|}{ Genotype (genotypic frequency) } & \multirow[t]{3}{*}{$P$ value } & \multirow{3}{*}{$\begin{array}{l}\text { Additive effect } \\
\qquad(a \pm S E)\end{array}$} \\
\hline & & \multicolumn{3}{|c|}{ Mean } & \multirow[t]{2}{*}{$\mathrm{RSD}^{2}$} & & \\
\hline & & $\mathrm{CC}(0.25)$ & $\mathrm{TC}(0.50)$ & $\mathrm{TT}(0.25)$ & & & \\
\hline \multirow{12}{*}{$\begin{array}{l}\text { Polymorphism } \\
\text { g. } 69,144,312 \\
\text { C>T }(K L F 3)\end{array}$} & Carcass weight adj42 & $650^{\mathrm{a}}$ & $657^{\mathrm{b}}$ & $666^{c}$ & 1 & $2 \times 10^{-7}$ & $-7.70 \pm 1.45$ \\
\hline & Back weight adj42 & $186^{\mathrm{a}}$ & $190^{\mathrm{b}}$ & $196^{c}$ & 2 & $2 \times 10^{-12}$ & $-5.05 \pm 0.69$ \\
\hline & Breast weight adj42 & $160^{\mathrm{a}}$ & $162^{\mathrm{b}}$ & $166^{c}$ & 2 & 0.0002 & $-3.08 \pm 0.82$ \\
\hline & Feet weight adj42 & $42^{c}$ & $41^{\mathrm{b}}$ & $40^{\mathrm{a}}$ & 2 & 0.0258 & $5.91 \pm 2.63$ \\
\hline & Feet yield & $4.2^{\mathrm{c}}$ & $4.1^{\mathrm{b}}$ & $4.0^{\mathrm{a}}$ & 7.1 & 0.0008 & $0.79 \pm 0.23$ \\
\hline & Intestine length & $157^{\circ}$ & $155^{\mathrm{b}}$ & $153^{\mathrm{a}}$ & 7 & 0.0028 & $2.07 \pm 0.99$ \\
\hline & Feed intake from 35 to 41 days adj 35 & $620^{\circ}$ & $594^{b}$ & $581^{a}$ & 7 & 0.0460 & $19.82 \pm 8.07$ \\
\hline & Efficiency from 35 to 41 days adj 35 & $0.39^{c}$ & $0.37^{b}$ & $0.36^{a}$ & 8.53 & 0.0150 & $0.02 \pm 0.01$ \\
\hline & Weight gain from 35 to 41 days adj 35 & $243^{c}$ & $224^{\mathrm{b}}$ & $209^{a}$ & 11 & 0.0005 & $17.16 \pm 4.63$ \\
\hline & Liver weight adj. 42 & $27^{c}$ & $26^{\mathrm{b}}$ & $25^{\mathrm{a}}$ & 4 & $4 \times 10^{-9}$ & $1.10 \pm 0.18$ \\
\hline & Gizzard weight adj.42 & $26^{c}$ & $25^{\mathrm{b}}$ & $24^{a}$ & 4 & 0.0003 & $0.97 \pm 0.26$ \\
\hline & Cholest. and trig. content adj. 42 & $123^{a}$ & $131^{\mathrm{b}}$ & $139^{c}$ & 6 & $9 \times 10^{-6}$ & $-8.09 \pm 1.79$ \\
\hline
\end{tabular}

CC, TC, and TT, single nucleotide polymorphism genotypes followed by genotype frequencies in the $F_{2}$ population. ${ }^{1}$ Type of polymorphism and overlapping genes. ${ }^{2} \mathrm{RSD}$ (relative standard deviation) is the absolute value of the coefficient of variation [RSD $=$ (standard deviation / average $) \times 100]$. a,b,c Values within a row with different superscripts differ significantly at $\mathrm{P}<0.05$.

When all of the markers were included in the model (KLF3, SLIT2, and PPARGC1A), significant associations $(P<0.05)$ with wing, head, carcass, back, drum, thigh, and feet weights, and back, drum, thigh, and feet yields, intestine length, feed intake, weight gain from 35 to 41 days, body weight at 41 and 42 days, and heart, liver, and gizzard weight were found in the $F_{2}$ population. In the TT reference population, significant associations $(P<0.05)$ with body weight at 21 days, abdominal fat weight, and abdominal fat yield were found.

When the effects of SLIT2 and PPARGC1A were included in the model in order to test the $K L F 3$ effect, no association was found $(P>0.05)$ in the $F_{2}$ population, and only an association with breast yield was found in the TT pure line $(P<0.05)$. When the effects of KLF3 and PPARGC1A were included in the model to test the SLIT2 effect, significant associations were found $(P<0.05)$ 
with the head, gizzard, and feet weight, and feet, back, drum, and thigh yields in the $\mathrm{F}_{2}$ population. In the TT population, significant associations $(P<0.05)$ were found with abdominal fat weight and yield, weight gain, feed conversion from 35 to 41 days, and feet and back yields.

\begin{tabular}{|c|c|c|c|c|c|c|c|c|}
\hline \multirow[t]{3}{*}{$\mathrm{F}_{2}$ population ${ }^{1}$} & \multirow[t]{3}{*}{ Trait } & \multicolumn{4}{|c|}{ Genotype (genotypic frequency) } & \multirow[t]{3}{*}{$P$ value } & \multirow{3}{*}{$\begin{array}{c}\text { Additive effect } \\
\qquad(\mathrm{a} \pm \mathrm{SE})\end{array}$} & \multirow{3}{*}{$\begin{array}{l}\text { Dominance effect } \\
\qquad(\mathrm{d} \pm \mathrm{SE})\end{array}$} \\
\hline & & \multicolumn{3}{|c|}{ Mean } & \multirow[t]{2}{*}{$\overline{\mathrm{RSD}^{2}}$} & & & \\
\hline & & Del/Del (0.17) & In/Del (0.51) & $\ln / \ln (0.32)$ & & & & \\
\hline \multirow{20}{*}{$\begin{array}{l}\text { Polymorphism } \\
\text { g. } 73,632,140 \\
\text {-/TTTCT } \\
\text { (PPARGC1A) }\end{array}$} & Wings weight adj.42 & $85^{c}$ & $83^{a}$ & $84^{b}$ & 1 & 0.0020 & $-0.43 \pm 0.34$ & $-1.10 \pm 0.47$ \\
\hline & Head weight adj.42 & $33^{a}$ & $35^{\mathrm{b}}$ & $36^{c}$ & 3 & $4 \times 10^{-8}$ & $1.44 \pm 0.24$ & $0.70 \pm 0.33$ \\
\hline & Carcass weight adj.42 & $657^{\mathrm{a}}$ & $672^{\mathrm{c}}$ & $659^{\mathrm{b}}$ & 1 & $3 \times 10^{-8}$ & $1.26 \pm 1.73$ & $14.00 \pm 2.43$ \\
\hline & Back weight adj42 & $196^{\circ}$ & $194^{\mathrm{b}}$ & $185^{\mathrm{a}}$ & 2 & 0.0010 & $-5.65 \pm 0.78$ & $3.50 \pm 1.10$ \\
\hline & Drum and thigh weight adj.42 & $215^{a}$ & $226^{c}$ & $225^{b}$ & 2 & $2 \times 10^{-7}$ & $5.16 \pm 0.99$ & $6.10 \pm 1.40$ \\
\hline & Breast weight adj42 & $161^{\mathrm{a}}$ & $168^{\mathrm{c}}$ & $164^{\mathrm{b}}$ & 2 & 0.0011 & $1.95 \pm 0.99$ & $5.20 \pm 1.40$ \\
\hline & Feet weight adj42 & $41^{\mathrm{b}}$ & $40^{\mathrm{a}}$ & $41^{\mathrm{b}}$ & 2 & $5 \times 10^{-6}$ & $0.44 \pm 0.27$ & $-1.40 \pm 0.38$ \\
\hline & Feet yield & $4.0^{\mathrm{b}}$ & $3.9^{\mathrm{a}}$ & $4.1^{\mathrm{c}}$ & 7.1 & $9 \times 10^{-7}$ & $0.07 \pm 0.03$ & $-0.10 \pm 0.04$ \\
\hline & Intestine length & $154^{b}$ & $151^{\mathrm{a}}$ & $156^{c}$ & 7 & 0.0003 & $1.02 \pm 1.27$ & $-4.30 \pm 1.43$ \\
\hline & Feed intake from 35 to 41 days & $594^{b}$ & $561^{a}$ & $599^{\circ}$ & 15 & 0.0069 & $4.44 \pm 11.53$ & $-35.00 \pm 12.06$ \\
\hline & Weight gain from 35 to 41 days & $226^{c}$ & $205^{\mathrm{a}}$ & $225^{\mathrm{b}}$ & 21 & 0.0030 & $-1.77 \pm 5.97$ & $-20.90 \pm 6.21$ \\
\hline & Body weight at 35 days & $823^{c}$ & $786^{a}$ & $814^{b}$ & 11 & 0.0238 & $-8.49 \pm 11.60$ & $-33.40 \pm 12.13$ \\
\hline & Body weight at 41 days & $1042^{c}$ & $984^{\mathrm{a}}$ & $1036^{b}$ & 11 & 0.0015 & $-5.96 \pm 15.03$ & $-56.50 \pm 15.69$ \\
\hline & Body weight at 42 days & $1009^{c}$ & $952^{a}$ & $1001^{b}$ & 11 & 0.0018 & $-8.34 \pm 14.70$ & $-54.80 \pm 15.35$ \\
\hline & Heart weight adj.42 & $7^{\mathrm{b}}$ & $6^{a}$ & $6^{a}$ & 4 & 0.0251 & $-0.10 \pm 0.14$ & $-0.40 \pm 0.15$ \\
\hline & Liver weight adj.42 & $26^{b}$ & $25^{\mathrm{a}}$ & $26^{b}$ & 2 & 0.0053 & $-0.08 \pm 0.23$ & $-1.00 \pm 0.32$ \\
\hline & Gizzard weight adj.42 & $24^{\mathrm{a}}$ & $25^{\mathrm{b}}$ & $26^{c}$ & 4 & 0.0002 & $0.91 \pm 0.32$ & $-0.70 \pm 0.44$ \\
\hline & Lungs weight dj.42 & $9^{c}$ & $8^{b}$ & $7^{\mathrm{a}}$ & 6 & $6 \times 10^{-6}$ & $-0.74 \pm 0.16$ & $-0.20 \pm 0.22$ \\
\hline & Cholesterol content adj.42 & $109^{c}$ & $91^{\mathrm{a}}$ & $96^{\mathrm{b}}$ & 7 & $3 \times 10^{-7}$ & $-6.70 \pm 1.59$ & $-11.60 \pm 2.20$ \\
\hline & Cholest. and trig. content adj. 42 & $137^{c}$ & $124^{a}$ & $126^{b}$ & 5 & 0.0100 & $-5.46 \pm 1.99$ & $-6.90 \pm 2.90$ \\
\hline
\end{tabular}

$\mathrm{Del} / \mathrm{Del}, \mathrm{In} / \mathrm{Del}$, and $\mathrm{Inl} / \mathrm{In}$, indel genotypes followed by genotype frequencies in the $\mathrm{F}_{2}$ population. ${ }^{1}$ Type of polymorphism and overlapping genes. ${ }^{2} \mathrm{RSD}$ (relative standard deviation) is the absolute value of the coefficient of variation [RSD = (standard deviation / average) $\times 100$ ]. ${ }^{a, b, c}$ Values within a row with different superscripts differ significantly at $P<0.05$.

\begin{tabular}{|c|c|c|c|c|c|c|c|}
\hline \multirow[t]{3}{*}{$\mathrm{F}_{2}$ population ${ }^{1}$} & \multirow[t]{3}{*}{ Trait } & \multicolumn{4}{|c|}{ Genotype (genotypic frequency) } & \multirow[t]{3}{*}{$P$ value } & \multirow{3}{*}{$\begin{array}{c}\text { Additive effect } \\
\qquad(a \pm S E)\end{array}$} \\
\hline & & \multicolumn{3}{|c|}{ Mean } & \multirow[t]{2}{*}{$\mathrm{RSD}^{2}$} & & \\
\hline & & $\mathrm{AA}(0.0)$ & $A C(0.51)$ & CC (0.49) & & & \\
\hline Polymorphism & Feet weight adj.42 & - & $41^{\mathrm{b}}$ & $39^{a}$ & 3 & $6 \times 10^{-14}$ & $2.48 \pm 0.31$ \\
\hline g. $74,737,073$ & Back yield & - & $18.9^{\mathrm{a}}$ & $19.2^{\mathrm{b}}$ & 3.8 & 0.0318 & $-0.25 \pm 0.12$ \\
\hline \multirow[t]{4}{*}{$\mathrm{C}>\mathrm{A}(S L I T 2)$} & Drum and thigh yield & - & $21.8^{\mathrm{b}}$ & $21.5^{\mathrm{a}}$ & 4.1 & 0.0278 & $0.30 \pm 0.13$ \\
\hline & Feet yield & - & $4.1^{\mathrm{b}}$ & $3.9^{\mathrm{a}}$ & 6.9 & $3 \times 10^{-8}$ & $0.18 \pm 0.03$ \\
\hline & Cholesterol content adj.42 & - & $131^{\mathrm{a}}$ & $141^{b}$ & 6 & 0.0001 & $-7.79 \pm 1.98$ \\
\hline & Cholest. and trig. content adj.42 & - & $103^{a}$ & $110^{\mathrm{b}}$ & 4 & 0.0010 & $-9.34 \pm 2.81$ \\
\hline
\end{tabular}

$A A, A C$, and $C C$, single nucleotide polymorphism genotypes followed by genotype frequencies in the $F_{2}$ population. ${ }^{1}$ Type of polymorphism and overlapping genes. ${ }^{2} \mathrm{RSD}$ (relative standard deviation) is the absolute value of the coefficient of variation [RSD = (standard deviation / average $) \times 100]$. a,b,c Values within a row with different superscripts differ significantly at $\mathrm{P}<0.05$.

When the effects of KLF3 and SLIT2 were included in the model to test the PPARGC1A effect, significant associations $(P<0.05)$ with the wings, head, carcass, back, drums, thighs, feet, heart, liver, and gizzard weights, intestine length, body weight at 35 and 41 days, and drum, thigh, 
and feet yields were found in the $F_{2}$ population. In the TT population, significant associations were found $(P<0.05)$ with feet and liver weights, body weight at 21 days, feet, liver, and abdominal fat yields, and carcass yield after bleeding and plucking.

Table 4. Associations between different polymorphisms within KLF3, PPARGC1A, and SLIT2 $(P<0.05)$ and traits in the TT reference population $(\mathrm{N}=840)$.

\begin{tabular}{|c|c|c|c|c|c|c|c|c|}
\hline \multirow[t]{2}{*}{ Pure TT population 1} & \multirow[t]{2}{*}{ Trait } & \multicolumn{4}{|c|}{ Genotype (genotypic frequency) } & \multirow[t]{2}{*}{$P$ value } & \multirow{2}{*}{$\begin{array}{c}\text { Additive effect } \\
(a \pm S E)\end{array}$} & \multirow{2}{*}{$\begin{array}{l}\text { Dominance effect } \\
\qquad(\mathrm{d} \pm \mathrm{SE})\end{array}$} \\
\hline & & & Mean & & $\mathrm{RSD}^{2}$ & & & \\
\hline \multicolumn{9}{|l|}{ Polymorphism } \\
\hline g. $69,144,312$ & & CC (0.96) & TC $(0.04)$ & $\mathrm{TT}(0.00)$ & & & & \\
\hline $\mathrm{C}>\mathrm{T}(K L F 3)$ & Weight gain from 35 to 41 days adj. 35 & $529^{b}$ & $494^{\mathrm{a}}$ & - & 11 & 0.0201 & $35.33 \pm 15.16$ & \\
\hline g. $73,632,140$ & & Del/Del (0.11) & In/Del (0.44) & $\ln / \ln (0.45)$ & & & & \\
\hline /ТTTCT & Body weight at 21 days & $661^{c}$ & $636^{\mathrm{a}}$ & $640^{\mathrm{b}}$ & 11 & 0.0063 & $6.08 \pm 1.90$ & $3.76 \pm 2.47$ \\
\hline \multirow[t]{4}{*}{ (PPARGC1A) } & Liver yield & $2.3^{\mathrm{a}}$ & $2.4^{\mathrm{b}}$ & $2.4^{b}$ & 12.0 & 0.0002 & $-0.11 \pm 0.13$ & $0.59 \pm 0.18$ \\
\hline & Wing drumette yield & $3.8^{\mathrm{a}}$ & $3.9^{b}$ & $3.9^{\mathrm{b}}$ & 7.3 & 0.0003 & $-0.39 \pm 0.13$ & $0.17 \pm 0.18$ \\
\hline & Flat wing tip yield & $2.78^{\mathrm{a}}$ & $2.83^{c}$ & $2.81^{\mathrm{b}}$ & 5.04 & 0.0084 & $0.10 \pm 0.03$ & $0.01 \pm 0.04$ \\
\hline & Wing yield & $7.5^{\mathrm{a}}$ & $7.6^{\mathrm{b}}$ & $7.6^{\mathrm{b}}$ & 4.7 & 0.0032 & $3.41 \pm 1.72$ & $8.55 \pm 2.51$ \\
\hline g. $74,737,073$ & & $\mathrm{AA}(0.08)$ & $\mathrm{AC}(0.44)$ & $\mathrm{CC}(0.48)$ & & & & \\
\hline \multirow[t]{7}{*}{$\mathrm{C}>\mathrm{A}(\mathrm{SLIT2})$} & Weight gain from 35 to 41 days & $502^{\mathrm{a}}$ & $519^{b}$ & $523^{c}$ & 15 & 0.0424 & $-11.53 \pm 5.68$ & \\
\hline & Abdominal fat weight & $44^{\mathrm{a}}$ & $45^{\mathrm{b}}$ & $48^{c}$ & 24 & 0.0156 & $-2.10 \pm 0.85$ & \\
\hline & Abdominal fat yield & $1.96^{\mathrm{a}}$ & $2.02^{\mathrm{b}}$ & $2.12^{\mathrm{c}}$ & 22.34 & 0.0139 & $-0.09 \pm 0.03$ & \\
\hline & Wing drumette yield & $3.94^{c}$ & $3.89^{b}$ & $3.82^{\mathrm{a}}$ & 7.28 & 0.0015 & $0.07 \pm 0.02$ & \\
\hline & Flat wing tip yield & $2.80^{\circ}$ & $2.78^{\mathrm{b}}$ & $2.76^{\mathrm{a}}$ & 5.25 & 0.0453 & $0.02 \pm 0.01$ & \\
\hline & Wing yield & $7.63^{\circ}$ & $7.57^{\mathrm{b}}$ & $7.49^{\mathrm{a}}$ & 1.85 & 0.0008 & $0.08 \pm 0.03$ & \\
\hline & Back yield & $11.82^{\mathrm{c}}$ & $11.82^{\mathrm{b}}$ & $11.61^{\mathrm{a}}$ & 5.79 & 0.0032 & $0.15 \pm 0.05$ & \\
\hline
\end{tabular}

CC, TC, and TT, single-nucleotide polymorphism genotypes followed by genotype frequencies in the TT reference population; Del/Del, In/Del, and In/ln, indel genotypes followed by genotype frequencies in the TT reference population; $\mathrm{AA}, \mathrm{AC}$, and $\mathrm{CC}$, single-nucleotide polymorphism genotypes followed by genotype frequencies in the TT reference population. ${ }^{1}$ Type of polymorphism and overlapping genes. ${ }^{2} \mathrm{RSD}$ (relative standard deviation) is the absolute value of the coefficient of variation [RSD $=$ (standard deviation / average) $\times 100]$. a,b,c Values within a row with different superscripts differ significantly at $\mathrm{P}<0.05$.

\section{DISCUSSION}

This study was conducted using a four-step approach. Firstly, we selected possible positional candidate genes based on previous QTL studies, and then we proceeded with polymorphism identification followed by single and multiple marker association tests. The association tests were conducted in two populations: a segregating $F_{2}$ population, in order to identify potential genetic markers, followed by a pure line for validation purposes. The $F_{2}$ population was selected based on the most informative $F_{1}$ families (based on the large number of genotype possibilities for the three polymorphisms studied); therefore, not all families used had both parents being heterozygous, so we expected to lose some genotypes in the $F_{2}$ family. Two novel SNPs and one 6-bp InDel were identified in three positional/functional candidate genes, which were located in a QTL region on GGA4 previously identified as associated with body weight at 35 and 41 days and drum and thigh yield. The SNP g. 69,144,312 bp C>T was located in a non-coding region of exon 2 of KLF3. The InDel was identified at $\mathrm{g} .73,632,140 \mathrm{bp}-/ \mathrm{TTTCT}$ in the beginning of the first intronic region of PPARGC1A. The last mutation was located at $\mathrm{g}$. 74,737,073 bp C>A within intronic region 10 of SLIT2. The minor allele frequency of these polymorphisms ranged from 0.025 to 0.361 , indicating that they are still segregating in the populations studied. 
Deviations from the HWE can indicate that inbreeding and/or genetic selection has occurred. The allelic frequency of allele T for $K L F 3$ in the pure broiler line was $2 \%$, and that of allele C was $98 \%$. Despite the high frequency of allele C, KLF3 was in HWE (P > 0.05), indicating that no selection is occurring at this locus.

\section{Single marker association test}

$K L F 3$ has an important function in muscle development, adipogenesis, and erythropoiesis, which are associated with muscle and fat deposition (Funnell et al., 2012). The results presented in Table 1 indicate that KLF3 was associated with body parts, internal organs, body yields, and body weight in the $F_{2}$ population. Significant associations were observed with adjusted back weight $(P$ $\left.=2.0 \times 10^{-12}\right)$, adjusted liver weight $\left(P=4.9 \times 10^{-9}\right)$, and adjusted carcass weight $\left(P=2.0 \times 10^{-7}\right)$. There was also an interesting association with adjusted breast weight, with an additive effect of $\sim 3 \mathrm{~g}$ for the $\mathrm{T}$ allele. For weight gain from 35 to 41 days, an association in the $\mathrm{F}_{2}$ population $(\mathrm{P}<$ 0.05 ) was found, which was confirmed in the TT population $(P<0.05)$ (Table 4), where an allelic substitution effect of the unfavorable allele ( $T$ ) for the favorable allele (C) led to an improvement of $35.33 \mathrm{~g}$ in the pure line population.

PPARGC1A is involved in energy metabolism (mitochondrial biogenesis), white fat differentiation, and muscle fiber-type switching (Corton and Brown-Borg, 2005). PPARGC1A is expressed in abdominal fat tissue in broilers (Larkina et al., 2011) and backfat in pigs (Erkens et al., 2006). Previous studies have demonstrated the use of PPARGC1A as a potential marker for selection against abdominal fat in chickens (Wu et al., 2006), feed conversion in pigs (Stachowiak et al., 2007), and milk fat in cattle (Weikard et al., 2005), indicating its relationship with fat deposition in farm animals. In the present study, no associations were found between PPARGC1A and abdominal fat in either population analyzed. However, PPARGC1A was associated with adjusted cholesterol $\left(P=3.2 \times 10^{-7}\right)$ and cholesterol and triglyceride content $(P<0.05)$ in the $F_{2}$ population (Table 2). The insertion of $6 \mathrm{bp}$ in PPARGC1A decreased cholesterol and cholesterol and triglyceride levels. Animals with homozygous (In/ln) and heterozygous genotypes had the lowest values when compared with the homozygous deletion, indicating a dominance effect caused by the insertion of $6 \mathrm{bp}$ in PPARGC1A. This effect could not be validated in the TT population, because those traits were not measured in the pure line. PPARGC1A was associated with several other traits in the $\mathrm{F}_{2}$ population (Table 2), and exhibited overdominance for adjusted carcass and breast weight and dominance for adjusted drum and thigh weight. For body weight at 35, 41, and 42 days of age, there was an underdominance effect of this InDel. In the pure line, dominance was more important than additive effects for liver weight and wing yield. PPARGC1A was also associated with body weight at 21 days in the TT population, with the additive effect being more important for that trait (Table 4).

SLIT2 interacts with proteins that affect cell adhesion and movement in embryonic development, the activity of growth factors, and even modulation of their own activities (Holmes and Niswander, 2001). Since the AA genotype for the SLIT2 SNP was not found in the $F_{2}$ population, only the additive effect of this SNP was tested. SLIT2 was strongly associated with feet weight and yield $\left(P=3.26 \times 10^{-8}\right)$. Associations between SLIT2 and cholesterol content $(P<0.05)$ and back, drum, and thigh yield were identified $(P<0.05)$ in the $F_{2}$ population (Table 3$)$. The association with back yield found in the $F_{2}$ was confirmed in the pure line $(P<0.05)$. In the pure line TT, SLIT2 was also associated with weight gain from 35 to 41 days $(P<0.05)$, abdominal fat $(P<0.05)$, and wingrelated traits (Table 4), which are economically important characteristics for the poultry industry. 
Regarding the QTL mapped for body weight at 35 and 41 days by Ambo et al. (2009), the InDel (PPARGC1A) was associated with those traits in the $\mathrm{F}_{2}$ population, and $K L F 3$ was associated with weight gain from 35 to 41 days adjusted for body weight at 35 days. SLIT2 was associated with drum and thigh yield in the $\mathrm{F}_{2}$ population and PPARGC1A with drum and thigh weight adjusted to body weight at 42 days, which are related to the QTLs previously mapped by Baron et al. (2010). These results indicate that the QTLs identified in the target region of GGA4 might be explained by the effects of these genes.

\section{Multiple marker association test}

Results of the multiple marker association test indicated that the associations observed with KLF3 could be a residual effect of the PPARGC1A and SLIT2 polymorphisms. Only PPARGC1A was associated with body weight at 35 and 41 days, wing, carcass, back, drum, thigh, heart, and liver weights, and intestine length in the $\mathrm{F}_{2}$ population. SLIT2 was also associated with back yield. PPARGC1A and SLIT2 together were associated with head, feet, and gizzard weights, and yields of drums, thighs, and feet. However, in the single marker association test, SLIT2 was not associated with head and gizzard weights, and PPARGC1A was not associated with drum and thigh yield, but PPARGC1A was associated with adjusted drum and thigh weight, indicating the effect of the adjustment on this association. The QTL mapped by Ambo et al. (2009) for body weight at 35 and 41 days and by Baron et al. (2010) for drum and thigh yield can be partly explained by the effects of PPARGC1A and SLIT2.

In the TT population, PPARGC1A and SLIT2 were associated with abdominal fat and feet yields using a multiple marker association test. SLIT2 was also associated with abdominal fat weight, indicating its influence on fat characteristics. Associations of SLIT2 with feed conversion and feet yield were only identified when a multiple marker association test was conducted. Using the same methodology, PPARGC1A was also associated with feet and liver weights, feet yield, and post-bleeding and plucking carcass weight, and KLF3 was associated with breast yield. The use of a multiple marker association test allowed the identification of additional associations that were not detected by the single marker test, indicating its importance in this type of analysis. For example, SLIT2 was associated with feed conversion, which is one of the most important traits in poultry production.

The results of this study allowed the identification of several gene associations in both populations $\left(\mathrm{F}_{2}\right.$ and reference $\left.\mathrm{TT}\right)$, and indicated that more than one gene might be involved in the same traits and certain genes may mask the effects of other genes. In conclusion, our results suggest that genes for the production traits evaluated in this study are important, and their potential use as markers to improve selection in poultry breeding programs should be investigated further.

\section{Conflicts of interest}

The authors declare no conflict of interest.

\section{ACKNOWLEDGMENTS}

The authors are grateful for support from Universidade de São Paulo and the Embrapa Suínos e Aves National Research Center. The $F_{2}$ population was subsidized by the PRODETAB 
project \#038-01/01, and the TT reference population by Conselho de Desenvolvimento Científico e Tecnológico (CNPq, grant \#481755/2007-1, Brazilian Government). F. Pértille was funded by $\mathrm{CNPq}$ and the Fundação de Amparo à Pesquisa do Estado de São Paulo (FAPESP). R. Zanella is an early investigator fellow (BJT) for the CNPq, A.M Felício was supported by a grant from the CNPq, and L.L. Coutinho received a productivity fellowship from the CNPq.

\section{REFERENCES}

Ambo M, Campos RDLR, Moura ASMT, Boschiero C, et al. (2008). Genetic linkage maps of chicken chromosomes 6, 7, 8, 11 and 13 from a Brazilian resource population. Sci. Agric. 65: 447-452.

Ambo M, Moura ASAMT, Ledur MC, Pinto LFB, et al. (2009). Quantitative trait loci for performance traits in a broiler $\mathrm{x}$ layer cross. Anim. Genet. 40: 200-208.

Ankra-Badu GA, Le Bihan-Duval E, Mignon-Grasteau S, Pitel F, et al. (2010). Mapping QTL for growth and shank traits in chickens divergently selected for high or low body weight. Anim. Genet. 41: 400-405.

Baron EE, Moura ASAMT, Ledur MC, Pinto LFB, et al. (2010). QTL for percentage of carcass and carcass parts in a broiler $x$ layer cross. Anim. Genet. 42: 117-124.

Barrett JC, Fry B, Maller J and Daly MJ (2005). Haploview: analysis and visualization of LD and haplotype maps. Bioinformatics 21: 263-265.

Campos RLR, Nones K, Ledur MC, Moura ASAMT, et al. (2009). Quantitative trait loci associated with fatness in a broiler-layer cross. Anim. Genet. 40: 729-736.

Corton JC and Brown-Borg HM (2005). Peroxisome proliferator-activated receptor y coactivator 1 in caloric restriction and other models of longevity. J. Gerontol. A Biol. Sci. Med. Sci. 60: 1494-1509.

Erkens T, Van Poucke M, Vandesompele J, Goossens K, et al. (2006). Development of a new set of reference genes for normalization of real-time RT-PCR data of porcine backfat and longissimus dorsi muscle, and evaluation with PPARGC1A. BMC Biotechnol. 6: 41.

Esterbauer H, Oberkofler H, Krempler F and Patsch W (1999). Human peroxisome proliferator activated receptor gamma coactivator 1 (PPARGC1) gene: cDNA sequence, genomic organization, chromosomal localization, and tissue expression. Genomics 62: 98-102.

Ewing B, Hillier I, Wendl MC and Green P (1998). Base-calling of automated sequencer traces using phred. I. Accuracy assessment. Genome Res. 8: 175-185.

Felício AM, Boschiero C, Baliero JCC, Ledur MC, et al. (2013). Polymorphisms in FGFBP1 and FGFBP2 genes associated with carcass and meat quality traits in chickens. Genet. Mol. Res. 12: 208-222.

Fulton JE (2012). Genomic selection for poultry breeding. Anim. Frontiers 2: 30-36.

Funnell APW, Norton LJ, Mak KS, Burdach J, et al. (2012). The CACCC-binding protein KLF3/BKLF represses a subset of KLF1/EKLF target genes and is required for proper erythroid maturation in vivo. Mol. Cell Biol. 32: 3281-3292.

Gordon D, Abajian C and Green P (1998). Consed: a graphical tool for sequence finishing. Genome Res. 8: 195-202.

Hocking PM, Morrice DM, Law AS and Burt DW (2012). Many quantitative trait loci for feather growth in an $F_{2}$ broiler $x$ layer cross collocate with body weight loci. Br. Poult. Sci. 53: 162-167.

Holmes G and Niswander L (2001). Expression of slit-2 and slit-3 during chick development. Dev. Dyn. 222: 301-307.

Jacobs PS (1985). PHRED: A generator for natural language interfaces. EECS Department, University of California, Berkeley.

Jennen DGJ, Vereijken ALJ, Bovenhuis H, Crooijmans RPMA, et al. (2004). Detection and localization of quantitative trait loci affecting fatness in broilers. Poult. Sci. 83: 295-301.

Kidd T, Bland KS and Goodman CS (1999). Slit is the midline repellent for the robo receptor in Drosophila. Cell 96: 785-794.

Larkina T, Sazanova A, Fomichev K, Barkova O, et al. (2011). Expression profiling of candidate genes for abdominal fat mass in domestic chicken Gallus gallus. Genetika 47: 1140-1144.

Mackay TFC (2001). The genetic architecture of quantitative traits. Annu. Rev. Genet. 35: 303-339.

McSpadden K, Caires K and Zanella R (2013). The effect of Mycobacterium avium subspecies paratuberculosis exposure on animal health. Acta Sci. Vet. 41: 1095.

Nassar MK, Goraga ZS and Brockmann G (2013). Quantitative trait loci segregating in crosses between New Hampshire and White Leghorn chicken lines: III. Fat deposition and intramuscular fat content. Anim. Genet. 44: 62-68.

Nones K, Ledur M, Ruy D, Baron E, et al. (2006). Mapping QTLs on chicken chromosome 1 for performance and carcass traits in a broiler x layer cross. Anim. Genet. 37: 95-100.

Nones K, Ledur M, Zanella E, Klein C, et al. (2012). Quantitative trait loci associated with chemical composition of the chicken carcass. Anim. Genet. 43: 570-576. 
Peixoto JO, Tessmann AL, Saatkamp MG, Prado D, et al. (2011). População referência para validação de estudos genômicos e descoberta de genes em frango de corte. In: Anais da $48^{a}$ Reunião Anual da Sociedade Brasileira de Zootecnia, Belém.

Pérez-Enciso M and Misztal I (2004). Qxpak: a versatile mixed model application for genetical genomics and QTL analyses. Bioinformatics 20: 2792-2798.

Rabie TSKM, Crooijmans RPMA, Bovenhuis H, Vereijken ALJ, et al. (2005). Genetic mapping of quantitative trait loci affecting susceptibility in chicken to develop pulmonary hypertension syndrome. Anim. Genet. 36: 468-476.

Rönnegård L and Valdar W (2011). Detecting major genetic loci controlling phenotypic variability in experimental crosses. Genetics 188: 435-447.

Stachowiak M, Szydlowski M, Cieslak J and Switonski M (2007). SNPs in the porcine PPARGC1A gene: Interbreed differences and their phenotypic effects. Cell Mol. Biol. Lett. 12: 231-239.

Sue N, Jack BHA, Eaton SA, Pearson RCM, et al. (2008). Targeted disruption of the basic Krüppel-like factor gene (KLF3) reveals a role in adipogenesis. Mol. Cell Biol. 28: 3967-3978.

Weikard R, Kühn C, Goldammer T, Freyer G, et al. (2005). The bovine PPARGC1A gene: molecular characterization and association of an SNP with variation of milk fat synthesis. Physiol. Genomics 21: 1-13.

Wu GQ, Deng XM, Li JY, Li N, et al. (2006). A potential molecular marker for selection against abdominal fatness in chickens. Poult. Sci. 85: 1896-1899.

Zanella R, Settles ML, McKay SD, Schnabel R, et al. (2011). Identification of loci associated with tolerance to Johne's disease in Holstein cattle. Anim. Genet. 42: 28-38.

Zhou H, Deeb N, Evock-Clover C, Ashwell C, et al. (2006). Genome-wide linkage analysis to identify chromosomal regions affecting phenotypic traits in the chicken. I. Growth and average daily gain. Poult. Sci. 85: 1700-1711. 